\title{
Economic purification of recombinant uricase by artificial oil bodies
}

\author{
Fatemeh Saadat ${ }^{*}$, Peter Macheroux ${ }^{2}$, Houshang Alizadeh $^{3}$ and Seyed Hadi Razavi ${ }^{4}$
}

\begin{abstract}
Rasburicase is an expensive treatment used to control hyperuricemia caused by tumour lysis syndrome (TLS). In this study, a non-chromatographic method was designed based on nano-oil bodies for convenient and economical purification of the recombinant uricase. For this purpose, two chimaeras were synthesized with a different arrangement of the uricase, caleosin and intein fragments. After confirming the protein expression by measuring the uricase activity at $293 \mathrm{~nm}$, purification was conducted through oil-body construction. The results were resolved on the 12\% SDSPAGE gel. Finally, the stability of the oil bodies was examined against different salts, surfactants, temperatures, and pH values. According to our results, the overexpression of uricase-caleosin chimaera under the T7 promoter in Escherichia coli led to the production of soluble protein, which was successfully purified by artificial oil bodies. The active uricase was subsequently released through the self-splicing of intein. Further investigations highlighted the importance of the free C-terminus of caleosin in constructing artificial oil bodies. Moreover, surfactants and low temperature, in contrast to salts, improved the stability of oil bodies. In conclusion, caleosins are an efficient purification tag reducing the cost of purification compared to conventional chromatography methods.
\end{abstract}

Keywords: Caleosin, Downstream processing, Intein, Nanoemulsion, Triacylglycerol, Urate oxidase

\section{Graphical Abstract}

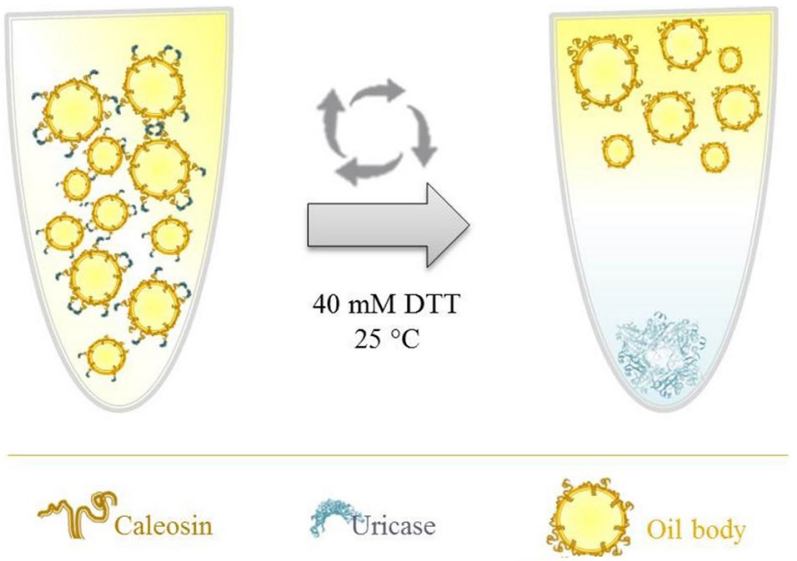

\footnotetext{
*Correspondence: f.saadat@ut.ac.ir

${ }^{1}$ Independent Department of Biotechnology, College of Agriculture

and Natural Resources, University of Tehran, Karaj, Iran

Full list of author information is available at the end of the article
}

(c) The Author(s) 2022. Open Access This article is licensed under a Creative Commons Attribution 4.0 International License, which permits use, sharing, adaptation, distribution and reproduction in any medium or format, as long as you give appropriate credit to the original author(s) and the source, provide a link to the Creative Commons licence, and indicate if changes were made. The images or other third party material in this article are included in the article's Creative Commons licence, unless indicated otherwise in a credit line to the material. If material is not included in the article's Creative Commons licence and your intended use is not permitted by statutory regulation or exceeds the permitted use, you will need to obtain permission directly from the copyright holder. To view a copy of this licence, visit http://creativecommons.org/licenses/by/4.0/. 


\section{Introduction}

Uricase or urate oxidase (EC 1.7.3.3) is a homotetrameric enzyme that catalyses the oxidation of uric acid during purine catabolism. In contrast to most living organisms, the gene encoding the enzyme has become dysfunctional in the human lineage owing to some nonsense mutations (Kratzer et al. 2014). Although several advantages have been suggested for the evolutionary removal of uricase in humans, excessive uric acid levels are associated with the risk of hyperuricemia, gout, high blood pressure, metabolic syndrome, diabetes as well as heart and kidney diseases (Álvarez-Lario and Macarrón-Vicente 2010). Hyperuricemia is also a part of tumour lysis syndrome (TLS) that can be fatal in one-third of patients (Mayne et al. 2008). Therefore, a recombinant uricase from Aspergillus flavus, termed rasburicase, has been approved by the Food and Drug Administration (FDA) to control uric acid levels. However, treatment with this drug is expensive-as much as 7500 \$ per day for a $70 \mathrm{~kg}$ person. Therefore, approaches to reduce the cost of treatment are highly desirable. According to economic analysis, the purification of uricase using an aqueous two-phase system (ATPS) instead of chromatography could save about $4000 \$$ per gram by reducing capital, consumables, and labour (Torres-Acosta et al. 2016).

ATPS has been known for the separation and concentration of cell organelles, proteins, nucleic acids, and low molecular weight compounds since the early 1960s (Raja et al. 2012). This water-in-water (W/W) emulsion is usually prepared based on the incompatibility of two watersoluble components, e.g. polymers, kosmotropic salts, alcohols and/or surfactants. Although ATPS is easier and faster than chromatography, the material costs are still remarkable. Moreover, solvent recycling and unclear separation mechanisms are among the main barriers (Pereira et al. 2020). Despite higher viscosity and interfacial tensions of oil-in-water $(\mathrm{O} / \mathrm{W})$ emulsions, they lack the drawbacks of ATPS. Furthermore, O/W emulsion droplets are used for various applications, such as drug delivery and bioavailability, encapsulation, and the food industry (Chao and Shum 2020).

Oil bodies are naturally formed using neutral lipids, phospholipids, and membrane proteins. The latter component constitutes the smallest part; however, that is the most critical in terms of the construction and stability of oil bodies. The amphiphilic nature of proteins allows them to coat oil particles, reduce the interfacial tension, and stabilize dispersions (Lam and Nickerson 2013). Oleosin and caleosin are the two best-known structural proteins of oil bodies (Purkrtová et al. 2015). Since oleosins were discovered about 30 years earlier than caleosins, more investigations have applied them for protein purification (Chiang et al. 2005, 2007; Liu et al. 2008; Choi and
Chang 2009), protein targeting (Karg and Kallio 2009; Montesinos et al. 2016; Huang et al. 2017), bioencapsulation (Chang et al. 2013), enzyme immobilization (Chiang et al. 2006), and antibody production (Tseng et al. 2011). However, caleosins have the advantage to make smaller oil bodies, which are more useful in drug delivery (Chiang et al. 2011, 2012) and bioavailability (Chen et al. 2005). Owing to these advantages, we have thus focused on the purification of recombinant uricase using the nano-oil bodies containing caleosin instead of oleosin.

\section{Material and methods}

\section{Construction of expression plasmids}

The full-length sequence of uricase-intein-caleosin (UC) was custom-synthesized (GeneralBiosystems, U.S.A.) and cloned into the pET28 $\alpha$ vector (University of Tehran, Iran). The pET-UC plasmid template was used to synthesize the caleosin-intein-uricase chimaera $(\mathrm{CU})$ by overlap extension (OE)-PCR through three steps. In the first step, each fragment was amplified separately using the primers listed in Table 1. The oligonucleotides were purchased from SinaColon (Iran) and Bioneer Inc. (South Korea). The produced intein harboured overlapping sequences for uricase and caleosin at its $\mathrm{C}$ and $\mathrm{N}$-terminus, respectively. Then, an equimolar amount of all three fragments was mixed for assembling the $\mathrm{CU}$ chimaera. Finally, the OE-PCR product was amplified using the oligonucleotide forward primer of caleosin (FC) and the reverse primer of uricase (RU). All the mentioned reactions were performed with Phusion high-fidelity DNA polymerase (Fermentas) using GeneAmp PCR System 9700 in the following program: pre-denaturing $\left(94{ }^{\circ} \mathrm{C}\right.$, $3 \mathrm{~min}), 25$ cycles of denaturing $\left(94{ }^{\circ} \mathrm{C}, 40 \mathrm{~s}\right)$, annealing, $\left(50{ }^{\circ} \mathrm{C}, 30 \mathrm{~s}\right)$, and extension $\left(72{ }^{\circ} \mathrm{C}, 1 \mathrm{~min} / \mathrm{kb}\right)$, and a final extension $\left(72{ }^{\circ} \mathrm{C}, 10 \mathrm{~min}\right)$. The desired PCR product was cloned into the pJET1.2/blunt and then digested with NotI and EcoRI to ligate into the expression vector pET28 $\alpha$. The accuracy of the recombinant constructs was confirmed by digestion and DNA sequence analysis (Microsynth, Austria) using the T7 sequencing primers.

Table 1 List of primer sequences used in this study

\begin{tabular}{ll}
\hline $\begin{array}{l}\text { Primer } \\
\text { name }\end{array}$ & Nucleotide sequence \\
\hline FU & GAATTCAAAATGTCTGCAGTAAAG \\
RU & GCGGCCGCATTATAACTTGGATTTCAAGGAAGA \\
FC & GAATTCAAAATGGGATCAGAGATCGACGATTC \\
RC & GCGGCCGCATTATCTACC \\
FIC & CTAAGATGAACATGGGTAGAGCCGTATCAGGTGATACTATCG \\
& TAATG \\
RIU & CTAGCGGCCTTTACTGCAGAATTATGGACAATGAATCCGTTG \\
\hline
\end{tabular}




\section{Bacterial strains and expression method}

The resulting plasmids were transferred into Escherichia coli Top10 and BL21 (DE3) for the recombinant construct amplification and expression, respectively. The cells were grown in LB medium containing $50 \mu \mathrm{g} \mathrm{ml}^{-1}$ kanamycin. Expression was optimized according to the Sambrook protocol (Sambrook et al. 1989) at a final $\mathrm{OD}_{600}$ of 0.7. Then, the cells were harvested by centrifugation $(4500 \times g$, $4{ }^{\circ} \mathrm{C}, 20 \mathrm{~min}$ ). The pellet was re-suspended in $3 \%$ of the initial LB volume of phosphate buffered saline $(\mathrm{pH} 8.5$, $0.137 \mathrm{M} \mathrm{NaCl}, 0.027 \mathrm{M} \mathrm{KCl}, 0.01 \mathrm{M} \mathrm{Na}_{2} \mathrm{HPO}_{4}$, and $0.0018 \mathrm{M} \mathrm{KH}_{2} \mathrm{PO}_{4}$ ), and then lysed on ice by sonication using a LABSONIC P (Sartorius AG, Germany). Insoluble material was pelleted by centrifugation, and the soluble fraction was stored at $-20^{\circ} \mathrm{C}$ for further analyses.

\section{Protein purification}

The procedure for protein purification was carried out as described by Tai et al. (Tai et al. 2002). In brief, $250 \mu \mathrm{l}$ of the extracted proteins, $150 \mu \mathrm{g}$ phosphatidylcholine (SigmaAldrich) and $15 \mathrm{mg}$ olive oil were suspended in $1 \mathrm{ml}$ of $0.1 \mathrm{M}$ sodium phosphate buffer ( $\mathrm{pH}$ 7.5). After mixing, three times sonication with $30 \%$ amplitude was done on ice for $20 \mathrm{~s}$ for the constitution of artificial oil bodies (AOBs). After centrifugation $\left(10,000 \times g, 4{ }^{\circ} \mathrm{C}, 15 \mathrm{~min}\right)$, the AOBs were collected and subjected to the desired $\mathrm{pH}$ or $40 \mathrm{mM}$ DTT for $16 \mathrm{~h}$ to release the target protein. Finally, the oil and aqueous phases were separated by centrifugation and each phase was analysed by SDS-PAGE and enzyme assay.

\section{Protein purity and molecular weight determination}

The purity of the proteins was determined on $12 \%$ of sodium dodecyl sulfate-polyacrylamide gel electrophoresis (SDS-PAGE). Gel electrophoresis was performed using Mini-PROTEAN Tetra Cell (BioRad) and proteins were stained with Coomassie blue R-250. A prestained protein ladder (ThermoFisher, 26616) was used to determine the molecular weight of the proteins.

\section{Microscopy of AOBs}

The size and shape of AOBs constituted with and without the chimaera proteins were observed under a light microscope (Zeiss Axioplan 2, Germany). The result was interpreted by ImageJ software (version 1.8.0) (Schneider et al. 2012).

\section{AOBs stability test}

The AOB's stability was measured by turbidity changes at $600 \mathrm{~nm}$ at room temperature (Chen et al. 2004). One millilitre of suspension mixture was placed in a disposable cuvette and treated with different parameters, including salts, surfactants, $\mathrm{pH}$, and temperature.

\section{Uricase activity assay}

The uricase activity was determined by continuous spectrophotometry. The reaction solution contained $0.11 \mathrm{mM}$ uric acid (Carl Roth) prepared in $20 \mathrm{mM}$ boric acid buffer $\mathrm{pH}$ 9. The enzymatic reaction was monitored at $293 \mathrm{~nm}$ for $5 \mathrm{~min}$ using a SPECORD 205 Analytik Jena (Germany). Subsequently, the activity was calculated using the Lambert-Beer law (extinction coefficient at $293 \mathrm{~nm}=12.6 \mathrm{mM}^{-1} \mathrm{~cm}^{-1}$ ). A unit (U) of uricase activity was defined as the consumption of one micromole of uric acid per min at $\mathrm{pH} 9.0$ at $25^{\circ} \mathrm{C}$. Finally, the protein concentration was measured using Bradford assay (Bradford 1976) for calculating the specific activity.

\section{Molecular modelling and docking}

The intensive mode of Phyre2 (www.sbg.bio.ic.ac.uk/ phyre2) was utilized to predict the 3D structure of the chimaera proteins (Kelley et al. 2015). The c1r56H from protein data bank (PDB) was used for retrieving the uricase domain. Besides, 17 structures (including c3u0kA, c4i2yB, c2hpkA, d1dtla, c3evrA, c3sibA, c3dtpF, d1iq3a, and c3ek7A for caleosin, and c4o1rA, c2imzA, c2in0A, d1am2a, d1mi8a, c2keqA, c4o1sB, and c2jmzA for intein) were selected on the basis of sequence identity $(>88 \%)$ for the modelling of caleosin and intein. Subsequently, the created models were refined and verified using ModRefiner (https://zhanglab.ccmb.med. umich.edu/ModRefiner/) and SAVES v5.0 (http://servi cesn.mbi.ucla.edu/SAVES/), respectively (Colovos and Yeates 1993; Xu and Zhang 2011). Then, molecular docking was applied to predict the binding of modelled chimaeras against uric acid by SwissDock (www.swissdock. ch) (Grosdidier et al. 2011). A grid box of 30 points in all directions of L147 was defined with a flexibility of $3 \AA$. Finally, the outputs were compared by the free energy of ligand binding ( $\Delta$ Gbinding, $\mathrm{kcal} / \mathrm{mol}$ ). The macromolecular structures were visualized by BIOVIA Discovery Studio (version 3.5).

\section{Statistical analysis}

Each experiment was performed in three replications using freshly prepared samples. The collected data were analysed using $\mathrm{R}$ (version 3.6.3). The one-way analysis of variance (ANOVA) and two-sample Wilcoxon test was used to compare the results, and $p<0.05$ was considered a significant variation.

\section{Results and discussion}

\section{Expression of UC and CU chimaeras in E. coli}

The UC and CU chimaeras were successfully constructed and transformed into E. coli BL21. To determine the optimum expression conditions, the effect of 
temperature and inducer concentration were investigated. The best result was obtained with $1 \mathrm{mM} \mathrm{IPTG}$ at $20^{\circ} \mathrm{C}$ and overnight incubation.

The protein content of induced and non-induced recombinant strains was analysed using SDS-PAGE. Accordingly, the production of recombinant protein under the control of the T7 promoter led to the appearance of a sharp band in the soluble fraction of the cell lysate (Fig. 1). Although a molecular mass of $72 \mathrm{kDa}$ was expected for both chimaeras, the expressed proteins exhibited a mobility corresponding to a molecular mass between 35 and $40 \mathrm{kDa}$. The analyses of the diluted sample revealed two distinct bands for uricase $(\sim 34 \mathrm{kDa})$ and

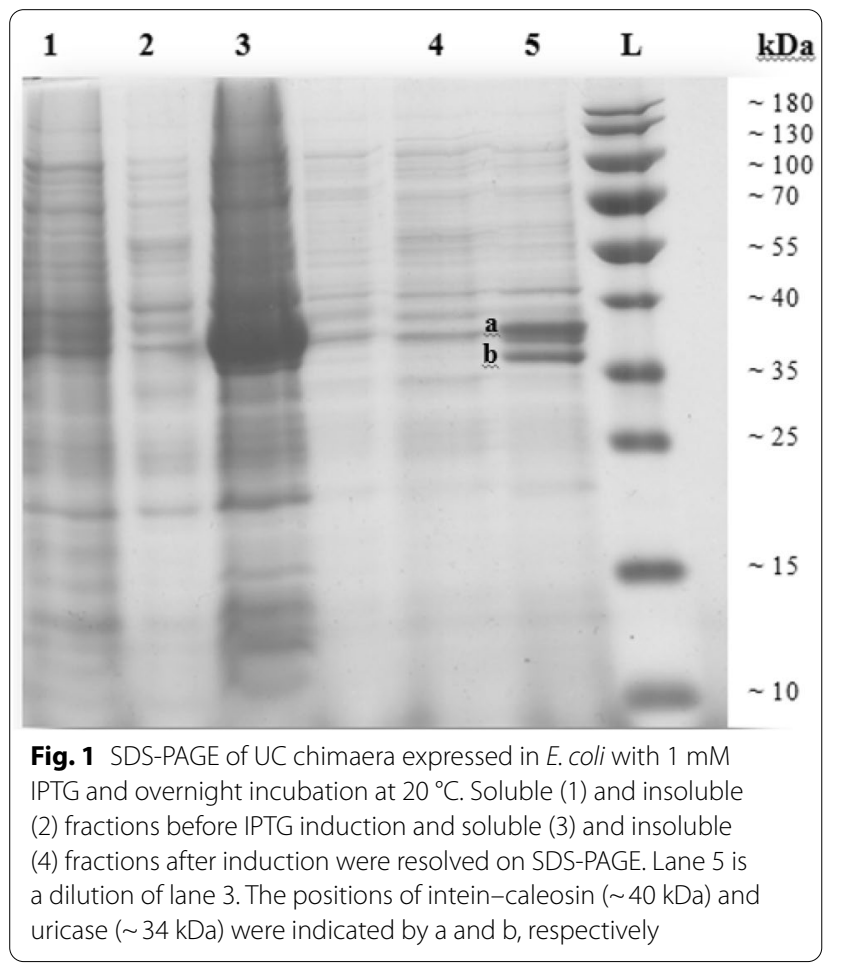

intein-caleosin $(\sim 40 \mathrm{kDa})$. Subsequently, the activity of the produced proteins was confirmed by uricase assay. Apparently, cleavage of the fusion protein has occurred under the reducing conditions used for SDS-PAGE. The faster migration of intein-caleosin could be caused by the binding of caleosin to available $\mathrm{Ca}^{2+}$ (Chen et al. 1999). In contrast, the multi-subunit structure of uricase is supposed to show less mobility on SDS-PAGE since they are resistant to denaturation by SDS (Pitts et al. 1974).

It is noteworthy that membrane proteins like caleosins are insoluble and get stuck in the pellet. However, the chimaera proteins were soluble.

\section{Purification of uricase by AOB system}

The purification of recombinant uricase was conducted using the AOB-based system. In the first step, AOBs were successfully formed using oil, phosphatidylcholine, and soluble fraction of cell lysate (with and without the chimaera proteins). The construction of AOBs was confirmed by microscopic visualization. As can be seen in Fig. 2, the AOBs were almost coalescence in the control condition, which was without the chimaera proteins. However, the presence of UC protein makes the nanoparticles (about $0.2 \mu \mathrm{m}$ ) (Fig. 2C). The comparison between the chimaera proteins indicates that $\mathrm{CU}$ is not a competent candidate for the construction of AOBs (Fig. 2B). It seems a free $\mathrm{C}$-terminus might be required for caleosin to build more stable and smaller droplets. However, it has been reported that the $\mathrm{N}$-terminus is also necessary for targeting caleosin to oil bodies (Purkrtová et al. 2015).

After centrifugation, the AOBs separated from the aqueous phase and washed to eliminate the non-specific proteins (Fig. 3, lanes 2 and 3). Then, uricase was released by inducing the self-cleaving intein through shifting the $\mathrm{pH}$ and/or using $40 \mathrm{mM}$ DTT at room temperature. Accordingly, uricase was retrieved in the aqueous phase (Fig. 3, lane 4), whereas intein-caleosin (Fig. 3, lane 1) remained in AOBs. Finally, all the mentioned fractions
(A) Control (Olive)

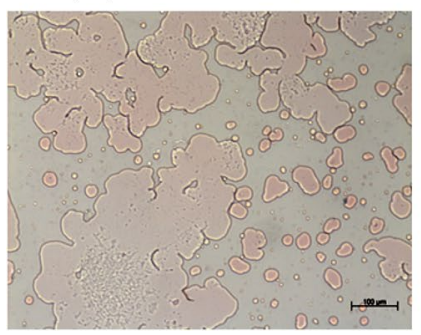

(B) $\mathrm{AOB}(\mathrm{CU})$

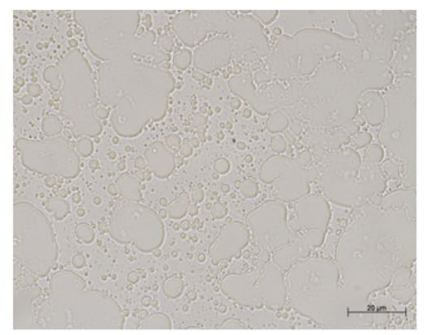

(C) $\mathrm{AOB}(\mathrm{UC})$

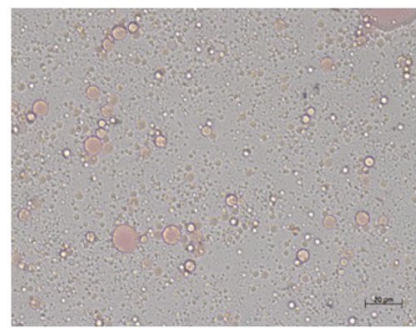

Fig. 2 Light microscopy of artificial oil bodies constituted with and without chimaera proteins. A Represents sonicated olive oil with no chimaera protein, while $\mathbf{B}$ and $\mathbf{C}$ show the sonicated olive oil in the presence of CU and UC chimaera, respectively. The bar represents $100 \mu \mathrm{m}$ for control and $20 \mu \mathrm{m}$ for two other 
were resolved on SDS-PAGE (Fig. 3). Repetition of purification steps improved the purity of the uricase (Fig. 3, lane 5).

The specific activity of the enzyme was increased from $0.53 \mathrm{U} / \mathrm{mg}$ in the crude extract to $15.2 \mathrm{U} / \mathrm{mg}$ in the purified enzyme, which is comparable with the purified uricases by chromatography columns (Fazel et al. 2014; Khaleghi and Asad 2021).

\section{AOB stability}

The AOB particles are shaped by balancing the attractive and repulsive forces of structural proteins (Tzen et al. 1992). Therefore, any change in $\mathrm{pH}$, ions or solvent that causes protein unfolding affects emulsion stability.

Our investigations on a wide range of $\mathrm{pH}$ values (3 to 11) revealed phase separation at the $\mathrm{pH}$ around the isoelectric point (pI) of caleosin ( $\mathrm{pH}$ 5). Indeed, a gradual increase in the emulsifying property occurs as the $\mathrm{pH}$ value gets far from the isoelectric point (Wang et al. 2019; Gao et al. 2021). Moreover, the AOB droplets aggregate at $\mathrm{pH} 3$ to 4 since the acidic environment increases surface hydrophobicity of oil bodies and thus leads to coalescence (Gao et al. 2021).

The effects of three concentrations of 50, 100, and $300 \mathrm{mM}$ of different salts, including $\mathrm{MgCl}_{2}, \mathrm{CaCl}_{2}, \mathrm{KCl}$, and $\mathrm{Na}_{2} \mathrm{SO}_{4}$, were also traced on $\mathrm{AOB}$ suspension for $15 \mathrm{~min}$ by turbidity tests. All the salts caused instability proportional to the ionic strength (Fig. 4A). However, the rapid reduction in turbidity by $0.3 \mathrm{M} \mathrm{CaCl}_{2}(p<0.05)$

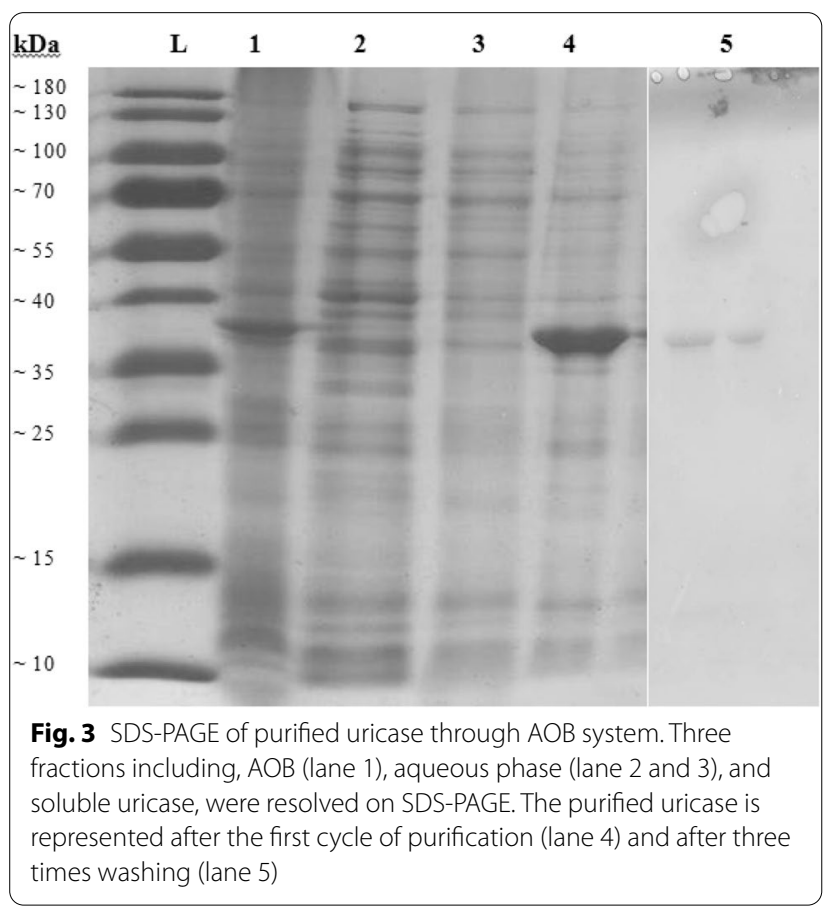

could occur as a result of the interaction of calcium with the EF_hand motif placed on the N-terminal domain of caleosin. This $\mathrm{Ca}^{2+}$-binding motif responds to biotic and abiotic stresses and plays a role in releasing triacylglycerols from oil bodies during seed germination (Poxleitner et al. 2006; Partridge and Murphy 2009; Shimada and Hara-Nishimura 2010). Although calcium caused sedimentation of AOBs, its low concentrations $(7.5 \mathrm{mM})$ have been used as a divalent to cross-link oil-body proteins and Pickering stabilizing (Liu et al. 2017). It has been reported that the Pickering emulsions need an oil volume fraction $(\phi)$ of greater than 0.2 (Guo et al. 2021).

In contrast to salts, surfactants are generally considered to act as emulsifying agents because of reducing surface tension, breaking hydrophobic interactions of proteins and increasing elasticity, viscosity, and electronegative repulsion (Sukhotu et al. 2014). Although using 2\% Tween 20 had no positive effect on AOB stability, adding $0.1 \%$ SDS rendered the suspension more stable (Fig. 4B).

A comparison between the stability of AOBs at $4{ }^{\circ} \mathrm{C}$ and room temperature showed that the lower temperatures prevent the emulsion coalescence (Fig. 4B), even if adding $0.1 \mathrm{M}$ salts (Fig. 4C). However, sensitivity to divalent cations $\left(\mathrm{Ca}^{2+}, \mathrm{Mg}^{2+}\right.$, and $\left.\mathrm{Zn}^{2+}\right)$ is not affected by temperature changes (Fig. $4 \mathrm{C}$ ). The same results have been reported for emulsions containing calcium or magnesium (Ramkumar et al. 2000; Romero-Guzmán et al. 2020). Our further investigations indicated that AOBs without the chimaera protein also show the same instability towards divalent salts (data not shown). Therefore, the reason for emulsion instability differs depending on the ionic strength and oil volume fraction.

\section{Effect of C- and N-terminal fusion on uricase activity}

Two chimaeras, $\mathrm{CU}$ and $\mathrm{UC}$, were designed to study the effect of $\mathrm{C}$ - and $\mathrm{N}$-terminal fusion on uricase activity. As shown in Fig. 5, the enzyme activity was lower in UC chimaeras $(p<0.05)$.

To evaluate the binding affinity of the chimaera proteins to the uric acid, the 3D structure was modelled using Phyre2. Subsequently, $88 \%$ and $92 \%$ of residues of $\mathrm{CU}$ and UC were represented at $>90 \%$ confidence (Fig. 6). Furthermore, a docking study by default parameters of SwissDock revealed no binding at the expected points of UC chimaera. However, several binding sites were predicted for $\mathrm{CU}$ chimaera, and one of them included the expected residues $(\Delta G=-6.97 \mathrm{kcal} / \mathrm{mol})$. Indeed, uricase consists of 301 residues in which the catalytic triad ( $\left.557^{*} \mathrm{~K} 10^{*} \mathrm{H} 256\right)$ were delimited by the six conserved residues (R176-Q228, N254-T57, and F159) (Gabison et al. 2008). As it is shown in Fig. 6, most of the defined residues (except $\mathrm{T} 57^{*} \mathrm{~K} 10^{*}$ ) were identified on CU chimaera. 



Fig. 4 Turbidity tests of $A O B s$ at $600 \mathrm{~nm}$. The measurements were conducted at room temperature and $\mathrm{pH} 7.5$ unless mentioned. The constituted oil bodies were exposed to $\mathbf{A}$ salt concentrations (50-300 mM) for $15 \mathrm{~min}$, B temperature and surfactants for $24 \mathrm{~h}$ and $\mathbf{C} 0.1 \mathrm{M} \mathrm{monovalent} \mathrm{(NaCl}$ and $\mathrm{KCl}$ ) and divalent $\left(\mathrm{MgCl}_{2}, \mathrm{CaCl}_{2}\right.$, and $\left.\mathrm{ZnSO}_{4}\right)$ salts for $24 \mathrm{~h}$ at $4^{\circ} \mathrm{C}$ and $25^{\circ} \mathrm{C}$

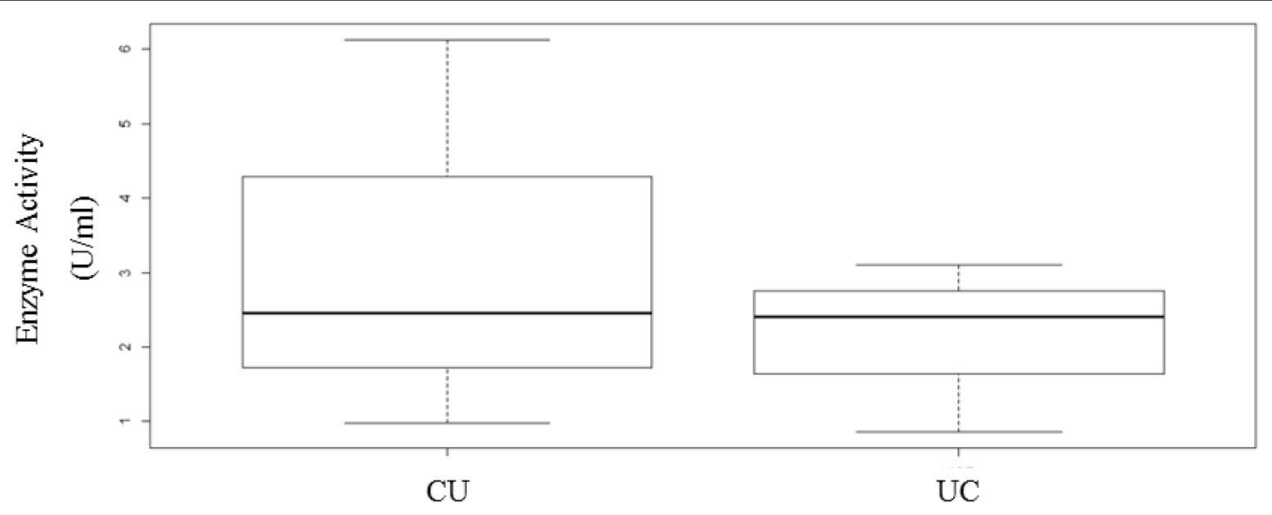

Fig. 5 Comparison of uricase activity of $C U$ and UC chimaeras to investigate the effects of tag on uricase activity. A non-parametric two-sample Wilcoxon test was used to compare the results $(p<0.05)$

\section{Conclusions}

Protein purification with a history of over 200 years is still one of the main challenges facing scientists during the production and study of proteins. Although chromatography is one of the most commonly used approaches for protein purification, it is associated with some drawbacks, including high cost, time-consuming and scale limitation. Compared to chromatography, the
AOB system is an easy, fast and inexpensive method that is feasible for recombinant protein purification.

Although protein purification using oil bodies has only been reported for oleosin, we selected caleosin as an efficient tool in constructing nano-oil bodies (Chen et al. 2004). In addition to convenient purification, stability and high surface absorption of the nano-oil bodies make them useful for immobilization and drug 


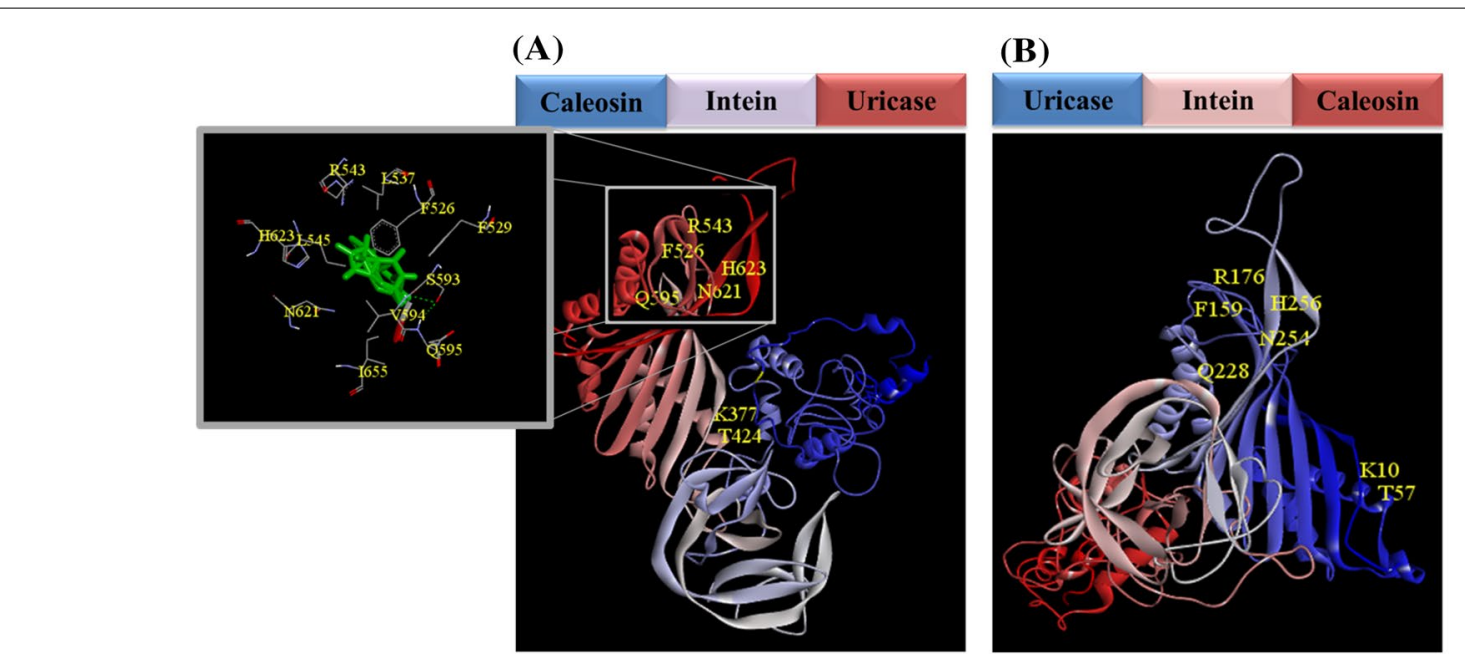

Fig. 6 The predicted structure for $\mathbf{A} C U$ and $\mathbf{B} \cup C$ chimaeras by Phyre2. The domain arrangements with the corresponding colours are shown on top of the shapes. The docking complex between $\mathrm{CU}$ chimaera and uric acid is also magnified

delivery of recombinant proteins like uricase. Moreover, constituted oil bodies can be used as biocompatible and renewable emulsifiers in the pharmaceuticals, cosmetics, and food industries to retrieve other parts of production costs. Therefore, our procedure would be more cost-effective than conventional chromatography methods.

\section{Abbreviations}

AOB: Artificial oil bodies; ATPS: Aqueous two-phase system; FDA: Food and Drug Administration; UC: Uricase-intein-caleosin chimaera; CU: Caleosinintein-uricase chimaera.

\section{Acknowledgements}

The authors would like to thank Dr. Ali Beirami, Dr. Amir Hossein Moini Zandi, Dr. Fariba Aboei, Dr. Bastian Daniel, Dr. Marina Toplak, MSc. Julia Messenlehner, and MSc. Reinmar Stefan Eggers for their support and assistance.

\section{Authors' contributions}

FS conceptualized, designed and performed the experiments and data analysis. HA, SR and PM supervised the project. HA and PM provided the experimental equipment and lab. FS wrote the manuscript in consultation with PM. All authors read and approved the final manuscript.

\section{Funding}

Not applicable.

\section{Availability of data and materials}

All data generated or analysed during this study are included in this published article.

\section{Declarations}

Ethics approval and consent to participate Not applicable.

\section{Consent for publication}

Not applicable.

\section{Competing interests}

The authors declare no competing interests.

\section{Author details}

${ }^{1}$ Independent Department of Biotechnology, College of Agriculture and Natural Resources, University of Tehran, Karaj, Iran. ${ }^{2}$ Institute of Biochemistry, Graz University of Technology, Graz, Austria. ${ }^{3}$ Department of Agronomy and Plant Breeding, University of Tehran, Karaj, Iran. ${ }^{4}$ Department of Food Science \& Technology, College of Agriculture \& Natural Resources, University of Tehran, Karaj, Iran.

Received: 26 October 2021 Accepted: 26 January 2022

Published online: 06 February 2022

\section{References}

Álvarez-Lario B, Macarrón-Vicente J (2010) Uric acid and evolution. Rheumatol Oxf Engl 49:2010-2015. https://doi.org/10.1093/rheumatology/keq204 Bradford MM (1976) A rapid and sensitive method for the quantitation of microgram quantities of protein utilizing the principle of protein-dye binding. Anal Biochem 72:248-254. https://doi.org/10.1016/00032697(76)90527-3

Chang MT, Tsai TR, Lee CY et al (2013) Elevating bioavailability of curcumin via encapsulation with a novel formulation of artificial oil bodies. J Agric Food Chem 61:9666-9671. https://doi.org/10.1021/jf4019195

Chao Y, Shum HC (2020) Emerging aqueous two-phase systems: from fundamentals of interfaces to biomedical applications. Chem Soc Rev 49:114-142. https://doi.org/10.1039/C9CS00466A

Chen JCF, Tsai CCY, Tzen JTC (1999) Cloning and secondary structure analysis of caleosin, a unique calcium-binding protein in oil bodies of plant seeds. Plant Cell Physiol 40:1079-1086. https://doi.org/10.1093/oxfordjournals. pcp.a029490

Chen MCM, Chyan CL, Lee TTT et al (2004) Constitution of stable artificial oil bodies with triacylglycerol, phospholipid, and caleosin. J Agric Food Chem 52:3982-3987. https://doi.org/10.1021/jf035533g

Chen MCM, Wang JL, Tzen JTC (2005) Elevating bioavailability of cyclosporine a via encapsulation in artificial oil bodies stabilized by caleosin. Biotechnol Prog 21:1297-1301. https://doi.org/10.1021/bp050030b

Chiang CJ, Chen CYP, Tzen JTC (2005) Efficient system of artificial oil bodies for functional expression and purification of recombinant nattokinase in Escherichia coli. J Agric Food Chem 53:4799-4804. https://doi.org/10. 1021/jf050264a 
Chiang CJ, Chen HC, Kuo HF et al (2006) A simple and effective method to prepare immobilized enzymes using artificial oil bodies. Enzyme Microb Technol 39:1152-1158. https://doi.org/10.1016/j.enzmictec.2006.02.024

Chiang CJ, Chen HC, Chao YP, Tzen JTC (2007) One-step purification of insoluble hydantoinase overproduced in Escherichia coli. Protein Expr Purif 52:14-18. https://doi.org/10.1016/j.pep.2006.07.008

Chiang CJ, Lin LJ, Chen CJ (2011) Caleosin-based nanoscale oil bodies for targeted delivery of hydrophobic anticancer drugs. J Nanopart Res 13:7127-7137. https://doi.org/10.1007/s11051-011-0630-6

Chiang CJ, Lin SC, Lin LJ et al (2012) Caleosin-assembled oil bodies as a potential delivery nanocarrier. Appl Microbiol Biotechnol 93:1905-1915. https:// doi.org/10.1007/s00253-011-3716-2

Choi SP, Chang HN (2009) Stable constitution of artificial oil body for the refolding of IGF1. Biotechnol Bioprocess Eng 14:161-167. https://doi.org/ 10.1007/s12257-008-0157-6

Colovos C, Yeates TO (1993) Verification of protein structures: patterns of nonbonded atomic interactions. Protein Sci Publ Protein Soc 2:1511-1519. https://doi.org/10.1002/pro.5560020916

Fazel R, Zarei N, Ghaemi N et al (2014) Cloning and expression of Aspergillus flavus urate oxidase in Pichia pastoris. Springerplus 3:395. https://doi.org/ 10.1186/2193-1801-3-395

Gabison L, Prangé T, Colloc'h N et al (2008) Structural analysis of urate oxidase in complex with its natural substrate inhibited by cyanide: mechanistic implications. BMC Struct Biol 8:32. https://doi.org/10.1186/ 1472-6807-8-32

Gao Y, Zhou L, Yao F, Chen F (2021) Effects of pH on the composition and physical stability of peanut oil bodies from aqueous enzymatic extraction. J Chem 2021:1-11. https://doi.org/10.1155/2021/2441385

Grosdidier A, Zoete V, Michielin O (2011) SwissDock, a protein-small molecule docking web service based on EADock DSS. Nucleic Acids Res 39:W270277. https://doi.org/10.1093/nar/gkr366

Guo X, Li X, Chan L et al (2021) Edible $\mathrm{CaCO}_{3}$ nanoparticles stabilized Pickering emulsion as calcium-fortified formulation. J Nanobiotechnology 19:67. https://doi.org/10.1186/s12951-021-00807-6

Huang J, Yang J, Guan L et al (2017) Expression of bioactive recombinant human fibroblast growth factor 10 in Carthamus tinctorius L. seeds. Protein Expr Purif 138:7-12. https://doi.org/10.1016/j.pep.2015.09.016

Karg SR, Kallio PT (2009) The production of biopharmaceuticals in plant systems. Biotechnol Adv 27:879-894. https://doi.org/10.1016/j.biotechadv. 2009.07.002

Kelley LA, Mezulis S, Yates CM et al (2015) The Phyre2 web portal for protein modeling, prediction and analysis. Nat Protoc 10:845-858. https://doi. org/10.1038/nprot.2015.053

Khaleghi R, Asad S (2021) Heterologous expression of recombinant urate oxidase using the intein-mediated protein purification in Pichia pastoris. 3 Biotech 11:120. https://doi.org/10.1007/s13205-021-02670-6

Kratzer JT, Lanaspa MA, Murphy MN et al (2014) Evolutionary history and metabolic insights of ancient mammalian uricases. Proc Natl Acad Sci USA 111:3763-3768. https://doi.org/10.1073/pnas.1320393111

Lam RSH, Nickerson MT (2013) Food proteins: a review on their emulsifying properties using a structure-function approach. Food Chem 141:975984. https://doi.org/10.1016/j.foodchem.2013.04.038

Liu JR, Duan CH, Zhao X et al (2008) Cloning of a rumen fungal xylanase gene and purification of the recombinant enzyme via artificial oil bodies. Appl Microbiol Biotechnol 79:225-233. https://doi.org/10.1007/ s00253-008-1418-1

Liu F, Ou S-Y, Tang C-H (2017) Ca ${ }^{2+}$-induced soy protein nanoparticles as Pickering stabilizers: fabrication and characterization. Food Hydrocoll 65:175-186. https://doi.org/10.1016/j.foodhyd.2016.11.011

Mayne N, Keady S, Thacker M (2008) Rasburicase in the prevention and treatment of tumour lysis syndrome. Intensive Crit Care Nurs 24:59-62. https://doi.org/10.1016/j.iccn.2007.06.002

Montesinos L, Bundó M, Izquierdo E et al (2016) Production of biologically active cecropin A peptide in rice seed oil bodies. PLoS ONE 11:e0146919. https://doi.org/10.1371/journal.pone.0146919

Partridge M, Murphy DJ (2009) Roles of a membrane-bound caleosin and putative peroxygenase in biotic and abiotic stress responses in Arabidopsis. Plant Physiol Biochem 47:796-806. https://doi.org/10.1016/j.plaphy. 2009.04.005
Pereira JFB, Freire MG, Coutinho JAP (2020) Aqueous two-phase systems: towards novel and more disruptive applications. Fluid Phase Equilib 505:112341. https://doi.org/10.1016/j.fluid.2019.112341

Pitts OM, Priest DG, Fish WW (1974) Uricase. Subunit composition and resistance to denaturants. Biochemistry 13:888-892. https://doi.org/10.1021/ bi00702a009

Poxleitner M, Rogers SW, Lacey Samuels A et al (2006) A role for caleosin in degradation of oil-body storage lipid during seed germination. Plant J Cell Mol Biol 47:917-933. https://doi.org/10.1111/j.1365-313X.2006. 02845.x

Purkrtová Z, Chardot T, Froissard M (2015) N-terminus of seed caleosins is essential for lipid droplet sorting but not for lipid accumulation. Arch Biochem Biophys 579:47-54. https://doi.org/10.1016/j.abb.2015.05.008

Raja S, Murty VR, Thivaharan V et al (2012) Aqueous two phase systems for the recovery of biomolecules-a review. Sci Technol 1:7-16. https://doi.org/ 10.5923/j.scit.20110101.02

Ramkumar C, Singh H, Munro PA, Singh AM (2000) Influence of calcium, magnesium, or potassium ions on the formation and stability of emulsions prepared using highly hydrolyzed whey proteins. J Agric Food Chem 48:1598-1604. https://doi.org/10.1021/jf990792k

Romero-Guzmán MJ, Petris V, De Chirico S et al (2020) The effect of monovalent $\left(\mathrm{Na}^{+}, \mathrm{K}^{+}\right)$and divalent $\left(\mathrm{Ca}^{2+}, \mathrm{Mg}^{2+}\right)$ cations on rapeseed oleosome (oil body) extraction and stability at pH 7. Food Chem 306:125578. https://doi.org/10.1016/j.foodchem.2019.125578

Sambrook J, Fritsch EF, Maniatis T (1989) Molecular cloning: a laboratory manual. Cold Spring Harbor Laboratory, New York

Schneider CA, Rasband WS, Eliceiri KW (2012) NIH Image to ImageJ: 25 years of image analysis. Nat Methods 9:671-675. https://doi.org/10.1038/nmeth. 2089

Shimada TL, Hara-Nishimura I (2010) Oil-body-membrane proteins and their physiological functions in plants. Biol Pharm Bull 33:360-363. https://doi. org/10.1248/bpb.33.360

Sukhotu R, Shi X, Hu Q et al (2014) Aggregation behaviour and stability of maize germ oil body suspension. Food Chem 164:1-6. https://doi.org/10. 1016/j.foodchem.2014.05.003

Tai SSK, Chen MCM, Peng CC, Tzen JTC (2002) Gene family of oleosin isoforms and their structural stabilization in sesame seed oil bodies. Biosci Biotechnol Biochem 66:2146-2153. https://doi.org/10.1271/bbb.66.2146

Torres-Acosta MA, Aguilar-Yáñez JM, Rito-Palomares M, Titchener-Hooker NJ (2016) Economic analysis of uricase production under uncertainty: contrast of chromatographic purification and aqueous two-phase extraction (with and without PEG recycle). Biotechnol Prog 32:126-133. https://doi. org/10.1002/btpr.2200

Tseng JM, Huang JR, Huang HC et al (2011) Facilitative production of an antimicrobial peptide royalisin and its antibody via an artificial oil-body system. Biotechnol Prog 27:153-161. https://doi.org/10.1002/btpr.528

Tzen JT, Lie GC, Huang AH (1992) Characterization of the charged components and their topology on the surface of plant seed oil bodies. J Biol Chem 267:15626-15634

Wang W, Cui C, Wang Q et al (2019) Effect of pH on physicochemical properties of oil bodies from different oil crops. J Food Sci Technol 56:49-58. https://doi.org/10.1007/s13197-018-3453-y

Xu D, Zhang Y (2011) Improving the physical realism and structural accuracy of protein models by a two-step atomic-level energy minimization. Biophys J 101:2525-2534. https://doi.org/10.1016/j.bpj.2011.10.024

\section{Publisher's Note}

Springer Nature remains neutral with regard to jurisdictional claims in published maps and institutional affiliations. 